$\mathbf{R}_{\text {ESEARCh }} \mathbf{P}_{\text {APER }} \longrightarrow \frac{\text { FOOD SCIENCE }}{\text { RESEARCH JOURNAL }}$

ISSN-0976-1276 Visit us : www.researchjournal.co.in

Volume $11 \mid$ Issue 2 | October, $2020 \mid$ 195-201

DOI : $10.15740 / \mathrm{HAS} / \mathrm{FSRJ} / 11.1 / 195-201$

\title{
Evaluation of sensory attributes of cauliflower slices under various pre-treatment and tray drying and microwave power drying condition
}

\author{
Vipin Kumar Verma, Devendra Kumar, Rupendra Singh, Pankaj Kumar and Devendra Singh
}

Cauliflower is one of the most important winter vegetable crop of india. Dehydrated cauliflower can be used to enhance the taste and nutritional value of various product such as vegetable soup, canned and extruded products etc.Experimental study was conducted to evaluate cauliflower slices using tray drying and microwave power drying techniques. Pre treatment of cauliflower slices as unblanched, blanched and blanched with $\mathrm{kms}$ and dried at different temperature $(45,55$ and $65^{\circ} \mathrm{C}$ ) and micro wave at different power level $(20 \mathrm{~W}, 40 \mathrm{~W}$ and $60 \mathrm{~W})$. The physio-chemical characteristics were evaluated just after preparation of cauliflower slices. Sensory characteristics (colour, flavour, taste, texture and overall acceptability) were evaluated for pre-treated cauliflower slices which dehydrated in tray dryer at 45,55 and $65^{\circ} \mathrm{C}$ temperature and in microwave power dryer at 20,40 and $60 \mathrm{~W}$ power. Sensory evolution was done using hedonic rating test method to measure the consumer acceptability. Results showed that highest score was obtained as 7.9 for colour at $65^{\circ} \mathrm{C}$ in $\mathrm{KMS}$ blanched condition whereas highest score for taste was obtained as 7.9 at $65^{\circ} \mathrm{C}$ in blanched condition in tray dryer. The maximum value of flavour (8.0) was obtained at $65^{\circ} \mathrm{C}$ in blanched condition whereas highest value of texture $(7.9)$ at $65^{\circ} \mathrm{C}$ in blanched condition in tray dryer in microwave dryer, the highest values of colour (7.9) was obtained at $60 \mathrm{~W}$ in $\mathrm{kms}$ blanched condition where as highest value of taste (7.9) at $60 \mathrm{~W}$ in unblanched conditions. The highest score of flavour (8.1) and texture (7.9) were found at $60 \mathrm{~W}$ in kms blanched condition in microwave power drying. Overall acceptability score was highest (7.92) in microwave power drying than tray drying (7.85) in kms blanched sample at $60 \mathrm{~W}$ power and $65^{\circ} \mathrm{C}$ temperature drying, respectively. Microwave power drying was found most suitable for kms blanched cauliflower slices at $60 \mathrm{~W}$ power level.

Key Words : Cauliflower slices, Microwave, Tray dryer, Colour, Taste, Flavour, Texture, Overall acceptability

How to cite this article : Verma, Vipin Kumar, Kumar, Devendra, Singh, Rupendra, Kumar, Pankaj and Singh, Devendra (2020). Evaluation of sensory attributes of cauliflower slices under various pre-treatment and tray drying and microwave power drying condition. Food Sci. Res. J., 11(2):195-201, DOI:10.15740/HAS/FSRJ/11.2/195-201.Copyright@2020: Hind Agri-Horticultural Society.

Email: vipincaet79@gmail.com

Associate Authors' :

Devendra Kumar, Rupendra Singh Pankaj Kumar and

Devendra Singh, Dr. Bhim Rao Ambedkar College of Agricultural Engineering and Technology, Etawah (U.P.) India

Email:devendrachaturvedi2008@gmail.com; rupendra.singh8195@ gmail.com,pankajkumarpk055@gmail.com and dsinghcsau@gmail. com 